\title{
A contribuição da Bioágua para a segurança alimentar e sustentabilidade no Semiárido Potiguar brasileiro
}

\author{
The contribution of the Bioágua program to food \\ security and sustainability in the semiarid sections \\ of the Brazilian state of Rio Grande do Norte \\ La contribución del "Programa Bioágua" para la \\ seguridad alimentaria y la sostenibilidad en la \\ región semiárida de Rio Grande do Norte
}

Christiane Fernandes dos Santos ${ }^{a}$

Zildenice Matias Guedes Maiab

Elisabete Stradiotto Siqueira ${ }^{c}$

Cimone Rozendo ${ }^{d}$

\begin{abstract}
aniversidade Federal Rural do Semiárido, Mossoró, RN, Brasil End. Eletrônico: chrisfernandes@ufersa.edu.br

${ }^{\mathrm{b}}$ Universidade Federal do Rio Grande do Norte, Natal, RN, Brasil End. Eletrônico: zildenice@hotmail.com

${ }^{\complement}$ Universidade Federal Rural do Semiárido, Mossoró, RN, Brasil End.Eletrônico: betebop@ufersa.edu.br

'Universidade Federal do Rio Grande do Norte, Natal, RN, Brasil End. Eletrônico: cimone.rozendo@gmail.com
\end{abstract}

doi:10.18472/SustDeb.v7nEsp.2016.18347

\section{RESUMO}

No semiárido potiguar brasileiro a má distribuição das chuvas compromete a sustentabilidade e a segurança alimentar dos agricultores familiares. Pesquisar sustentabilidade nessa região é se deparar com a necessidade de otimização da produção de alimentos, por meio do reúso da água. Logo, o presente estudo objetivou avaliar o Programa Bioágua Familiar, quanto à segurança alimentar e à sustentabilidade das famílias experimentadoras. Realizaram-se entrevistas com quatro agricultores das comunidades de Arrimo e Reforma, localizadas na zona rural do município de Janduís/RN. A tecnologia Bioágua Familiar aumenta o acesso à água, permitindo uma produção constante de frutas e hortaliças para o consumo familiar. Porém, a pesquisa revelou que a água cinza gerada é insuficiente para manter 
o sistema. A difusão dessa tecnologia depende de um conjunto de estratégias de convivência com o semiárido. Apreende-se que o Bioágua raramente poderá, sozinho, se constituir como alternativa sustentável para a produção de alimentos.

Palavras-chave: Bioágua. Segurança Alimentar. Agricultura Familiar.

\section{ABSTRACT}

In the semiarid sections of the Brazilian state of Rio Grande do Norte the irregular distribution of rainfall is jeopardizes the sustainability and the food security of farmers. Researching sustainability in this region means dealing with the need for optimizing food production through the reuse of water. The present study seeks to evaluate food security and sustainability of families involved in the "Bioágua Familiar" Program. We conducted interviews with four farmers in the Arrimo and Reforma communities, located in the rural municipality of Janduís, state of Rio Grande do Norte. The program's technology increases access to water and allows a constant production of fruit and vegetables for family consumption. However, it was found that the gray water generated is insufficient to maintain the system. The diffusion of this technology depends on a set of strategies that allow people to coexist with semi-aridity. It is concluded that the program on its own is not prone to constitute a sustainable alternative for food production.

Keywords: Bioágua Program. Food security. Family agriculture.

\section{RESUMEN}

En la región semiárida de Rio Grande do Norte, la mala distribución de precipitaciones compromete la sostenibilidad y la seguridad alimentaria de los agricultores familiares. Buscar la sostenibilidad en esta región significa enfrentarse a la necesidad de optimizar la producción de alimentos, a través de la reutilización del agua. Así, este estudio tuvo como objetivo evaluar el "Programa Bioágua Familiar", respecto a la seguridad alimentaria y la sostenibilidad de las familias experimentadoras. Se realizaron entrevistas con cuatro agricultores de las comunidades de Arrimo y Reforma, ubicadas en la zona rural del municipio de Janduís / Rio Grande do Norte. La tecnología "Bioágua Familiar" aumenta el acceso al agua, lo que permite una producción constante de frutas y verduras para el consumo familiar. Sin embargo, el estudio reveló que las aguas grises generadas es insuficiente para mantener el sistema. La difusión de esta tecnología depende de un conjunto de estrategias de convivencia con la región semiárida. Se aprende que el "Bioágua" pocas veces podrá, por sí solo, constituirse como una alternativa sostenible a la producción de alimentos.

Palabras clave: Bioágua. Seguridad Alimentaria. Agricultura Familiar.

\section{INTRODUÇÃO:}

Embora o Brasil tenha uma disponibilidade de água relevante à distribuição dos recursos hídricos, no contexto nacional é desigual se considerarmos que apenas $30 \%$ dos recursos hídricos estão disponíveis para $93 \%$ da população. Nesse sentido, a participação social nas políticas governamentais é fundamental para a superação de tal desigualdade (DE SOUZA PICCOLI et al. 2016).

O problema da irregularidade na distribuição das chuvas, e outros relacionados à gestão dos recursos hídricos (REBOUÇAS, 1997), é uma questão que se torna a cada dia mais preocupante no cenário mundial. Para as regiões do semiárido brasileiro essa realidade não é distinta, e já perpetua há bastante tempo. Quando a análise dessa escassez é feita com foco na agricultura familiar, a realidade se torna mais preocupante, pois além de estarem à margem de tecnologias e políticas públicas que possam vir fortalecer a sua vivência no campo, muitos dos agricultores familiares não dispõem de terra e água para, sequer, garantir a produção para o consumo alimentar. 
No semiárido brasileiro a sustentabilidade da agricultura familiar e, consequentemente, a segurança alimentar são fatores indissociáveis da questão da água. Portanto, pesquisar essa temática nessa região é se deparar com a necessidade de otimização da produção de alimentos. Dessa maneira, a opção por uma agricultura diferenciada, que busca tornar viável a produção agrícola, harmonicamente conduzida e associada à preservação e conservação ambiental, torna-se necessária, pois de acordo com Hespanhol (2002) a demanda de água para produção de alimentos depende de novas fontes de suprimento e uma gestão eficiente desse recurso.

Altieri (2000) afirma ser possível conciliar produção agrícola e preservação do meio ambiente. No entanto, reforça que para isso é preciso desenvolver agroecossistemas sustentáveis, que devem ser ao mesmo tempo produtivos, conservadores dos recursos naturais, viáveis economicamente, culturalmente sensitivos e socialmente justos. O projeto "Reúso da água domiciliar para produção de alimentos no Semiárido" ${ }^{1}$ visa colaborar com essa perspectiva de sustentabilidade na medida em que objetiva consolidar o Sistema Bioágua Familiar de Reúso da Água Cinza ${ }^{2}$ como alternativa para a produção de alimentos e redução da contaminação ambiental nos quintais das famílias agricultoras da região semiárida brasileira.

A presente pesquisa buscou respostas para as seguintes inquietações: que fatores limitam ou impulsionam a inserção de tecnologias de reúso da água no espaço rural? Como os(as) agricultores(as) familiares agem e se apropriam dessas novas tecnologias? Quais os impactos diretos do Bioágua na sustentabilidade local? Parte-se da compreensão que o Programa Bioágua se apresenta como uma alternativa agroalimentar adequada para a agricultura de base familiar, por basear-se na valorização dos recursos locais, na autonomia dos agricultores, tornando-os principais sujeitos no processo de produção de alimentos, do reúso da água, bem como da conservação do solo.

Torna-se pertinente tal estudo uma vez que o cenário é de alerta para os cuidados no manejo da água e do solo, assim como de alternativas que visem à sustentabilidade.

É considerando esse contexto que o presente trabalho objetivou avaliar o Programa Bioágua Familiar no que se refere, principalmente, à segurança alimentar e à sustentabilidade das famílias experimentadoras, em meio à má distribuição hídrica que assola o semiárido potiguar.

\section{TECNOLOGIAS SOCIAIS E SUSTENTABILIDADE}

A Revolução Verde e seus pacotes tecnológicos foram propostos como solução para o problema da fome que tem afligido a humanidade desde os tempos mais remotos. Somas vultosas foram destinadas a essa perspectiva com a promessa que não haveria mais famélicos no mundo. E a agricultura familiar continuaria marginalizada quando comparada ao modelo financiado pelo grande capital. Contudo, após décadas, o que se tem é um cenário desalentador devido aos impactos provenientes do modelo econômico e agroexportador (PLOEG, 2008).

Tal modelo tem servido para ocupar grandes terras, desapropriar camponeses, indígenas, quilombolas, ribeirinhos, escassear os recursos naturais, e não tem cumprido sua promessa de resolver o problema da fome. Ao contrário, segundo a Organização das Nações Unidas para Alimentação e Agricultura, calcula-se que 805 milhões de pessoas estão cronicamente subalimentadas em 2012-2014, o que significa que essas pessoas não têm, sequer, a quantidade mínima de nutrientes/dia (OLIVEIRA, 2015).

Diante dessa realidade, as inovações tecnológicas têm corroborado para a intensificação de um cenário ambíguo para o contexto rural, pois ao mesmo tempo em que melhoraram as condições de trabalho dos agricultores refletindo em maior quantidade produtiva, vê-se ao mesmo tempo a substituição dos trabalhadores por máquinas, principalmente nas grandes propriedades rurais (RIFKIN, 1995). Tal fato pode ser um propulsor do aumento no número de pessoas desempregadas, se acentuando de forma mais impactante no meio rural, uma vez que as máquinas substituem a mão de obra dos agricultores e desequilibram as oportunidades de comercialização, visto que a produtividade impulsionada por essa tecnologia produz desvantagens competitivas para a agricultura familiar. Nesse sentido, afirma Lamarche (1993, p. 13) "em alguns lugares, a exploração familiar é a ponta de lança do desenvolvimento 
da agricultura e de sua integração na economia de mercado; em outros, permanece arcaica e fundada essencialmente sobre a economia de subsistência".

A modernização da agricultura é abordada por Graziano Neto $(1985$, p. 27) na perspectiva de que seja reconhecido que não houve apenas uma mudança no âmbito técnico da agricultura, mas uma mudança nas relações sociais de produção. Segundo esse mesmo autor, "a modernização da agricultura não é outra coisa, para ser mais correto, que o processo de transformação capitalista da agricultura, que ocorre vinculado às transformações gerais da economia brasileira recente".

A industrialização do campo promove um rompimento das relações homem e natureza, além de ter em pouca conta as necessidades das famílias rurais. O que de fato predomina é a relação com os fatores artificiais, reconhecidos como os insumos externos, equipamentos tecnológicos, ou seja, a necessidade de auferir lucros para manter o sistema capitalista vigente (PLOEG, 2009). Já, Silva (1999) enfatiza que não se pode creditar unicamente à tecnologia as responsabilidades pelas mazelas oriundas do processo de modernização do campo, mas, sim, a um sistema social e econômico que visa apenas à apropriação dos meios de produção e dos seus resultados de forma exclusivamente privada. Além disso, os que pensam em tecnologia apropriada esquecem que o ritmo das transformações sociais, econômicas e tecnológicas é vertiginoso, e que a tecnologia apropriada de hoje será obsoleta amanhã, quando provavelmente começar a ser difundida entre os agricultores.

É válido ressaltar que a possibilidade de sobrevivência da agricultura familiar está creditada na própria capacidade de aproveitar tecnologias que melhor potencializam as suas vantagens competitivas, como uma maior eficiência na obtenção de produtos cujas etapas produtivas exigem atenção e cuidados especiais. Além disso, facilita arranjos cooperativos que combinam a competência familiar com a necessidade de contínuo intercâmbio de informação e de ações conjuntas por parte de seus participantes (BUAINAIN; SILVEIRA, 2003). Essas mesmas tecnologias devem ser fruto de um processo pedagógico e político que aproveita o saber das famílias produtoras, e possibilita um diálogo com estas, de modo que se apropriem dessas tecnologias a ponto de difundi-las de forma autônoma (DUQUE, 2008).

Flores (2001), ao questionar sobre a possibilidade de existência da agricultura familiar nesse novo século, afirma que são necessárias medidas políticas orientadas para o seu fortalecimento. Buainain e Silveira (2003) revelam que nos últimos anos as políticas públicas passaram a reconhecer a importância da agricultura familiar, principalmente por programas de crédito como o Programa Nacional de Fortalecimento da Agricultura Familiar (Pronaf). No entanto, alerta que é preciso reconhecer que o crédito ajuda, mas não é tudo. Sem tecnologia o familiar não consegue manter-se competitivo, e não conseguirá sobreviver. Apreende-se que, para a difusão de tecnologias apropriadas para agricultura familiar, é necessário considerar aspectos do local, as formas organizacionais de produção, bem como os saberes advindos da experiência dos próprios agricultores.

Destarte, pode-se compreender que tecnologia apropriada para os agricultores familiares são aquelas que:

[...] permitem a intensificação da geração de valor agregado em pequenas áreas, a redução da restrição colocada pela disponibilidade de mão de obra familiar e a exploração das vantagens organizacionais associadas à base familiar. Isto dá sentido à ideia de tecnologia para agricultura familiar. Em grande medida, essa tecnologia já existe, não requer maior esforço de pesquisa, e precisa apenas ser adaptada e disponibilizada (BUAINAIN; SILVEIRA, 2003, p. 2).

O aproveitamento das tecnologias não deve ser feito visando apenas dimensão econômica de um determinado grupo social, mas também visando a sua sustentabilidade de uma forma mais ampla. As tecnologias apropriadas, além de influenciarem a dimensão econômica, perpassam a questão ambiental, que consequentemente influenciam o social, tendo em vista a preservação dos recursos naturais, não apenas de maneira imediata, mas também para o usufruto das futuras gerações.

Diante do exposto, pode-se inferir que a agricultura familiar, para sobreviver às tecnologias "modernas" e aos impactos causados pela agricultura convencional, deve-se valer de políticas públicas que propiciem o uso de tecnologias apropriadas a sua realidade. No entanto, essas tecnologias devem 
ser "apropriadas" para além da sustentabilidade econômica, contribuindo assim para o convívio sustentável dos agricultores e agricultoras familiares.

\section{SEGURANÇA ALIMENTAR NA AGRICULTURA FAMILIAR}

A relação das crises alimentar, econômica e ambiental tem preocupado as populações humanas, sobretudo no que diz respeito às condições de garantia de segurança alimentar e nutricional que, por sua vez, refere-se à disponibilidade de alimentos em quantidade e qualidade ideais, como, também, às formas de produção e consumo alimentar. Do mesmo modo, é relevante reconhecer que entre as consequências da Revolução Verde, destaca-se a imposição de um padrão científico-tecnológico que provocou exacerbada demanda e dependência de insumos industriais e energias não renováveis. Associou-se, ainda, a intensificação da monocultura, provocando nos territórios rurais uma perda da agrobiodiversidade e do seu potencial sociocultural (SCHOTTZ, 2014).

Os sistemas tradicionais da agricultura familiar estão sendo constantemente pressionados pela extrema homogeneização induzida pelo avanço da modernização capitalista de produção de alimentos. Em contrapartida a essa tendência, o campesinato continua tendo, na biodiversidade e na policultura, suas principais fontes de trabalho que, antes de qualquer consciência ecológica, são muito mais uma manifestação dos seus interesses em garantir a oferta suficiente para o autoabastecimento das suas famílias (ALMEIDA, 1999). De acordo com Azevedo et al. (2011), a agroecologia, desenvolvida prioritariamente por agricultores familiares, tem um grande potencial de se constituir como uma estratégia intersetorial de promoção da saúde, considerando sua capacidade em fomentar democracia, autonomia, participação entre seus agentes e entre eles e a sociedade, além de incentivar o resgate de saberes e práticas tradicionais visando maior sustentabilidade nos níveis ambientais, sociais e econômicos.

Esse princípio tem sido alimentado pelas iniciativas dos agricultores, com apoio de organizações de assessoria, em desenvolver atividades de diversificação da produção e resgate de muitas espécies da fauna e flora nativa, que estavam perdendo sua importância no sistema produtivo que garantisse renda e soberania alimentar, inclusive, algumas delas, sofrendo ameaça de extinção. É o que enfatiza Canuto (1998) sobre a importância desse resgate para a sustentabilidade dos sistemas agrícolas locais e regionais.

Por outro lado, a Agroecologia, que é desenvolvida prioritariamente por agricultores familiares, tem o potencial de promoção da saúde no meio rural. Nas últimas décadas, tem merecida atenção a opção por uma agricultura diferenciada, que busca tornar viável a produção agrícola, harmonicamente conduzida e associada à preservação e conservação ambiental. Entretanto, para conciliar produção agrícola e preservação do meio ambiente é preciso desenvolver agroecossistemas sustentáveis, que devem ser ao mesmo tempo produtivos, conservadores dos recursos naturais, viáveis economicamente, culturalmente sensitivos e socialmente justos (ALTIERI, 2000).

O agricultor familiar considera sua terra um patrimônio que lhe proporciona um modo de vida pautado na própria vivência e reconhecimento dos recursos locais (fragilidades e potencialidades) disponíveis na sua unidade de trabalho. Essa percepção o incentiva a um manejo cuidadoso da terra. Sua atividade produtiva tem como primeiro objetivo o autoconsumo, mais precisamente na segurança alimentar de sua família, sendo comercializados apenas os excedentes da produção, o que leva o produtor a práticas de policultura e consórcios (WANDERLEY, 2013).

Como efeito, a policultura responde a diversas necessidades de consumo e, consequentemente, à segurança alimentar das famílias rurais. Também reflete uma medida de cautela ante as oscilações do mercado. Os consórcios permitem um aproveitamento melhor de propriedades geralmente com pouca área. Esse conjunto diversificado, além de ser menos favorável à difusão de pragas, permite um aproveitamento judicioso de todos os recursos. Por exemplo, o restolho das culturas serve para alimentação do rebanho, enquanto o esterco serve de adubo para as culturas. Finalmente, por ser a mão de obra constituída principalmente por membros da família, o responsável se preocupa com suas condições de trabalho (DUQUE, 2008). 
Assim, pensar em soberania e segurança alimentar e nutricional no semiárido, é pensar igualmente no desafio da sustentabilidade. Isso implica pensar nas ações e estratégias de produção que considerem como relevantes a identidade cultural e tradicional das pessoas do campo, a sociobiodiversidade e a natureza, viabilizando, assim, vida mais saudável aos seres humanos dessa região, bem como aos ecossistemas locais e regionais, fortalecendo, assim, os modos de vida do povo do semiárido (ROCHA, 2014).

\section{REÚSO DA ÁGUA NA PRODUÇÃO AGRÍCOLA FAMILIAR}

A escassez de água deve ser enfrentada considerando a simultaneidade de várias questões. De Souza Piccoli (2016), ao desenvolver uma proposta de educação ambiental relacionada ao enfrentamento dessa questão, sugere alguns temas geradores que participam das alternativas para minimização do problema, conforme Figura 1.

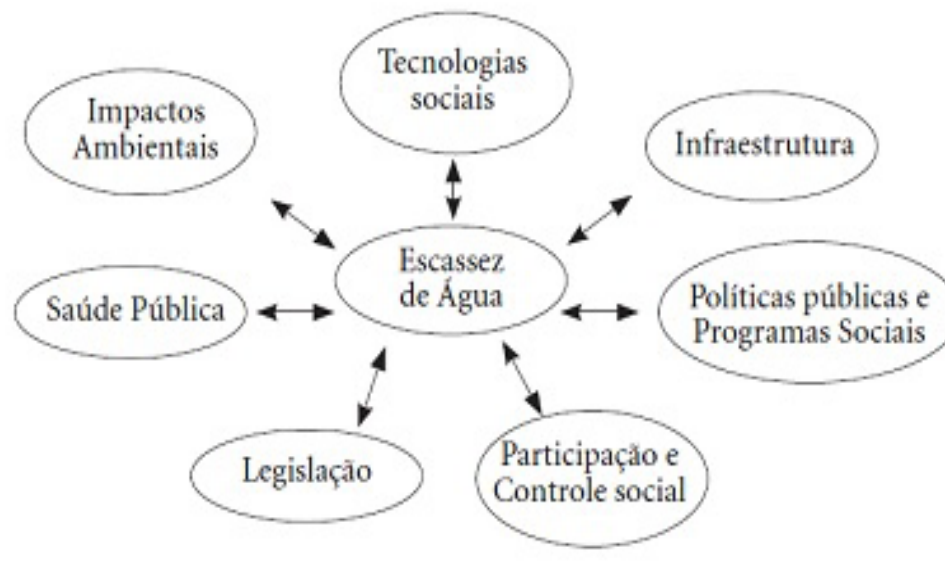

Figura 1 - Temas geradores relacionados à escassez de água

Fonte: DE SOUZA PICCOLI, et al. 2016, p. 802.

A reutilização de águas residuais contempla vários desses temas, pois é realizada por tecnologias específicas e representam a preocupação com duas questões fundamentais no século XXI, o abastecimento e acesso humano à água e a preocupação com o meio ambiente natural que é degradado em decorrência da disposição inadequada de resíduos e da má utilização da água. Nesse sentido, algumas experiências já apontam que outros caminhos vêm sendo percorridos por grandes países, tais como China, que nos últimos anos tem se preocupado em adquirir de Israel o conhecimento e tecnologias adequadas para mitigar os impactos provenientes das ações antrópicas sobre os recursos hídricos (SFREDO, 2011).

Do mesmo modo, algumas atividades econômicas têm implementado tecnologias que reutilizam as águas residuais para otimizar os custos da produção e torná-la mais viável. Um exemplo é a pesquisa apresentada por Soares et al. (2012), onde identificou-se que o processamento dos frutos do cafeeiro de café cereja descascado implica em grande utilização de água, e gera quantidade considerável de águas residuais, que potencialmente pode contaminar os recursos aquáticos.

É válido ressaltar, em países como Israel, que sofrem com a escassez de água, a preocupação com a gestão hídrica é prioridade. $E$, em consequência disso, a introdução de inovações norteia-se pelos princípios básicos da exploração máxima dos recursos hídricos convencionais, de recursos não convencionais, podendo-se citar as águas residuais, além da adoção de práticas de uso racional (ROCHA; SILVA; BARROS, 2010).

Assim, a preocupação com a reutilização das águas residuais trata-se de uma realidade percebida em diversos países e, no Brasil, uma das suas estratégias no semiárido nordestino é o programa "Bioágua Familiar", compreendido como um sistema de reutilização da água cinza para produção de alimentos na referida região. 
A tecnologia está sendo utilizada por agricultores do estado do Rio Grande do Norte, pioneiro na experimentação e difusão, apresentando-se como uma tecnologia de reutilização da água que possibilita a segurança alimentar e nutricional, por meio da produção diversificada de alimentos. Contribui com a redução da contaminação ambiental nos quintais das famílias agricultoras, e também para a sustentabilidade local.

\section{IDENTIFICAÇÃO E LOCO DA PESQUISA}

A presente pesquisa caracteriza-se como qualitativa, quanto a sua abordagem, na medida em que se busca compreender as inovações da agricultura familiar ante a escassez hídrica do semiárido potiguar, segundo a perspectiva dos participantes da situação estudada, para, a partir de então, fazer inferências diante das informações obtidas no percurso de todo o estudo.

Para tanto, foi realizada uma pesquisa de campo. Nessa etapa, como instrumento metodológico, optou-se pela realização de entrevista, que se fez através de um roteiro previamente elaborado, além de registros fotográficos. As entrevistas foram realizadas in loco com quatro (4) agricultores, que se apropriaram da tecnologia Bioágua Familiar, e realizam essa experiência em suas unidades de trabalho, localizadas nas comunidades de Arrimo e Reforma, zona rural do município de Janduís, no estado do Rio Grande do Norte.

No ano 2010, segundo o Instituto Brasileiro de Geografia e Estatística (IBGE), a população desse município era estimada em 5.345 habitantes, em uma área territorial de $305 \mathrm{~km}^{2}$, com 3.993 habitantes na cidade e 1.353 no campo. Esta, distribuída em aproximadamente 58 comunidades rurais.

Segundo a divisão regional do município supracitado apresentada por Santos e Moraes (2014), as comunidades anteriormente citadas pertencem à Região Seca, caracterizada pelos seguintes aspectos:

[...] relevo irregular e solo predominantemente areno-argiloso. A água é proveniente de cacimbões e cisternas; a vegetação nativa é constituída, principalmente de jurema, velame e pereiro. Nessa Região, os principais problemas enfrentados pela comunidade são falta de água e o desmatamento (SANTOS; MORAES, 2014, p.356).

A escolha pelas comunidades e agricultores, que colaboraram com esse estudo, não se deu de forma aleatória, mas pelo fato de as primeiras apresentarem características marcantes de escassez hídrica. E quanto aos sujeitos da pesquisa, por serem os primeiros, nesse município, a realizarem essa experiência de reúso da água cinza domiciliar.

Tendo em vista a necessidade de buscar respostas para as interrogações apresentadas na parte introdutória deste estudo, as perguntas foram distribuídas em quatro grupos principais: o processo de delineamento da Tecnologia Bioágua, sustentabilidade econômica, sustentabilidade ambiental e sustentabilidade social.

Assim, a análise dos resultados se constitui em um olhar coerente com a exigência de um trabalho científico. Sujeito, portanto, a outras percepções que possam evidenciar novas constatações aos resultados por hora apresentados.

\section{RESULTADOS E DISCUSSÕES}

\section{O PROCESSO DE DELINEAMENTO DA TECNOLOGIA BIOÁGUA}

As políticas de desenvolvimento implementadas na região Nordeste do Estado brasileiro nem sempre foram condizentes com as suas especificidades sociais, ambientais e econômicas, fator esse que acaba impondo entraves no seu processo de desenvolvimento (SANTOS, 2013). Nessa perspectiva, em seu estudo sobre o combate à seca e convivência no semiárido, Silva (2006, p.124) ressalta que "O caminho para a formulação de políticas apropriadas para o desenvolvimento regional, considerando 
suas condições naturais, é o aprofundamento dos estudos e do conhecimento da realidade local [...]". Além disso, afirma que as propostas e práticas que vêm sendo orientadas para a convivência no semiárido nordestino "[...] estão substancialmente ligadas a um paradigma de sustentabilidade do desenvolvimento que propõe a harmonização entre a justiça social, a prudência ecológica, a eficiência econômica, a diversidade cultural e a cidadania política".

Com isso, decorre o surgimento de um novo paradigma, a Convivência com o Semiárido, e o projeto Bioágua Familiar surge como possibilidade de fortalecer essa perspectiva e como meio de superação à escassez hídrica vivenciada pelos agricultores familiares do semiárido potiguar. É pertinente ressaltar que uma das principais questões que assolam o debate acerca da sustentabilidade nessa região é a convivência com os seus aspectos naturais. Embora o semiárido brasileiro seja um dos mais chuvosos do mundo, as tecnologias de captação da água das chuvas ainda são embrionárias no contexto da agricultura familiar, apesar de já demonstrarem avanços nos últimos anos.

Por meio do desenvolvimento de tecnologias de convivência com o semiárido, como o Bioágua, por exemplo, é possível desenvolver ações de valorização do conhecimento local, que se faz, sobretudo, por meio da inclusão das famílias. Infere-se, portanto, que o aprendizado para a convivência com o semiárido comece nas unidades de trabalho dos agricultores familiares, a partir da proposição de construção coletiva, onde os saberes advindos de suas práticas sejam evidenciados.

A tecnologia consiste em um processo de filtragem por mecanismos de impedimento físico e biológico dos resíduos presentes na água cinza, sendo a matéria orgânica biodegradada por uma população de microrganismos e minhocas. A água cinza é proveniente do uso doméstico, como pia de cozinha, chuveiro, tanque ou máquina de lavar (Figura 2-A). Essa água deve ser acondicionada em um tanque (Figura 2-B) que contém um filtro de duas camadas de material orgânico como húmus e serragem de madeira, e duas camadas de material inorgânico, cascalho e seixo rolado (SANTIAGO et al., 2012). E depois, depositada no tanque de reúso (Figura 2-C), de onde a água é bombeada para a irrigação dos canteiros de hortaliças (Figura 2-D) e demais culturas presentes nas unidades de Bioágua Familiar. 


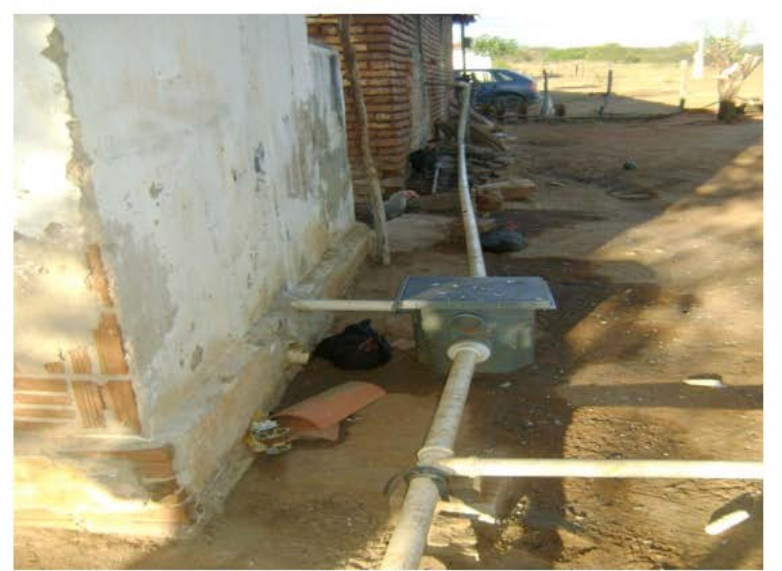

(A)

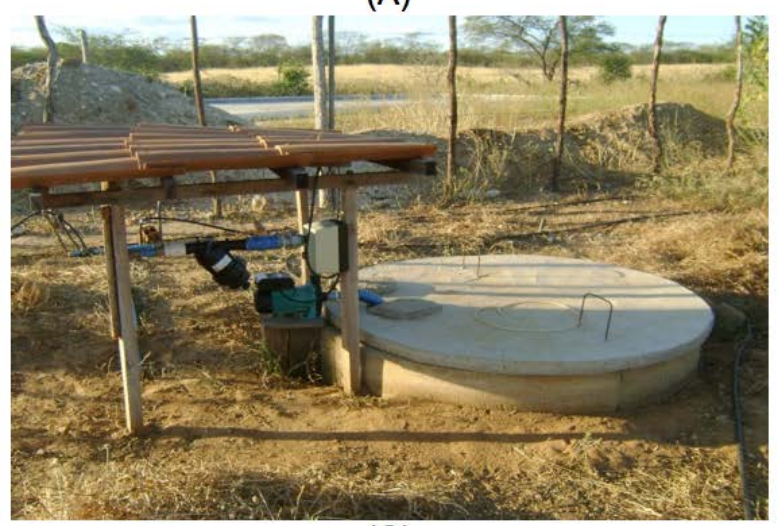

(C)

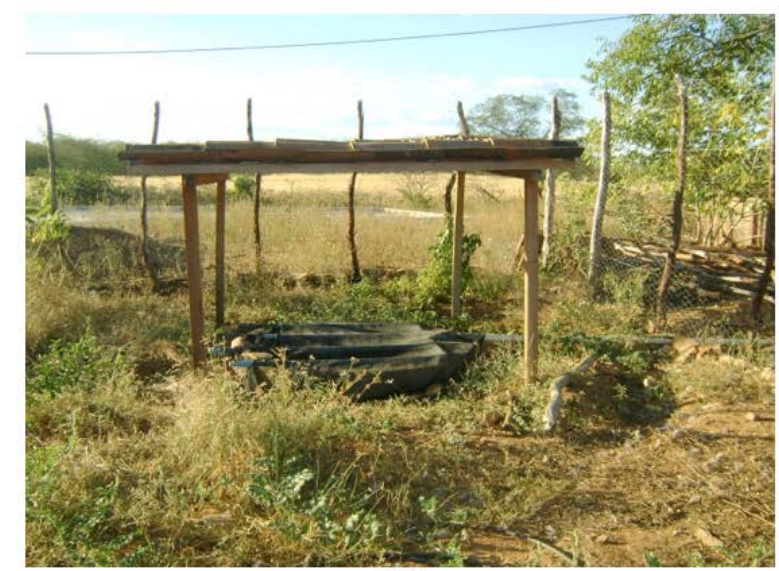

(B)

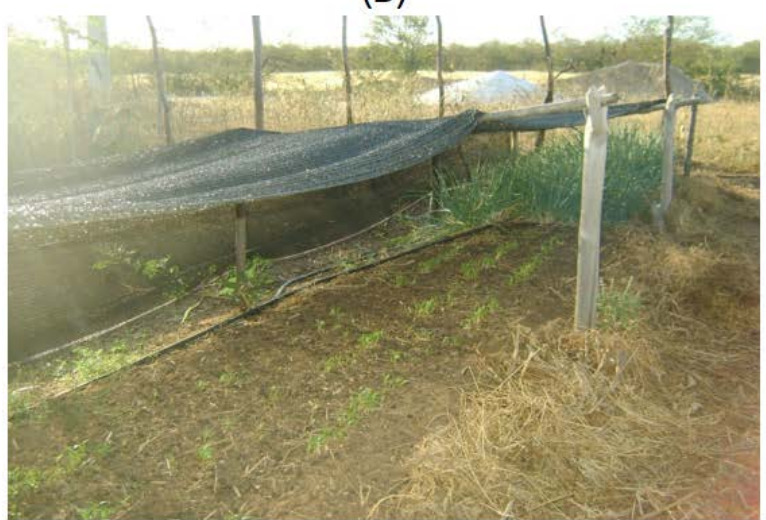

(D)

Figura 2 - Estrutura do bioágua familiar na comunidade Reforma/Janduís/RN

Fonte: Própria, 2015

Ao perguntar ao Entrevistado 1 quais os fatores que dificultam a implantação do Bioágua, afirmou que "O que mais dificulta a implantação do Bioágua é o convencimento das famílias, por não conhecerem como funciona, e também a mão de obra". Percebeu-se, de acordo com o relato, que uma possível limitação é a questão da mão de obra. Contudo, pode-se inferir que falta, por parte de alguns atores, maior credibilidade na utilização e valorização da tecnologia social, perpassando, portanto, o próprio interesse da família em experimentar esse sistema.

Sobre os fatores que limitam hoje a adesão ao Bioágua, revelou que:

A questão da água também dificulta, pois a água utilizada é do reúso, a água cinza como se chama, que sai das pias e do banho, acaba não sendo suficiente. No bioágua tem que ter um controle regular. No final de semana, quando tem mais gente em casa, a quantidade de água usada é maior, mas durante a semana é menor. Mas também tem que economizar água (ENTREVISTADO 1).

Corroborando com o mesmo entendimento, o Entrevistado 2 considera que: "O mais difícil é plantar. Porque a água de duas pessoas não é suficiente para manter. Tem vez que completo o Bioágua com a água do açude." Já o Entrevistado 3 revela: "[...] Quando foi implantado não tinha água, a casa era abastecida com carro-pipa, então tinha que economizar. Se a água do banho, da louça não dá, a gente dá uma ajuda com a água que vem de fora".

No que se refere à quantidade de água cinza produzida e aproveitada para a irrigação das plantas no Bioágua Familiar, e considerando o relato dos agricultores, apreende-se que existe uma contradição, pois ao mesmo tempo que a unidade Bioágua Familiar necessita de uma quantidade de água regular para poder se obter uma produção mais diversificada e constante, por outro lado vê-se com a obrigação de economizar a água utilizada nos afazeres domésticos em virtude da escassez hídrica 
que está vivenciando. Ora, se passa a ser utilizada menos água cinza, significa dizer que menos água será reutilizada no Bioágua, podendo comprometer a produção de frutas e hortaliças presente nessa unidade de produção familiar. Desse modo, pode-se evidenciar que o Bioágua não pode ser utilizado como fonte única de irrigação, devendo ser complementada.

Percebe-se que a maior dificuldade apresentada pelos agricultores em relação à implantação e manutenção do Bioágua Familiar está relacionada à pouca disponibilidade de água cinza utilizada pela família, em virtude do número de pessoas que a compõe. Entretanto, das famílias participantes dessa pesquisa, apenas duas atendem ou superam o número mínimo de pessoas por família (que é de quatro, segundo informações dos entrevistados) exigido na proposta de implantação do Bioágua Familiar. Assim, infere-se que há uma discrepância em relação à proposta da tecnologia e a realidade das famílias no que diz respeito a esse aspecto.

Perguntou-se, ainda, como os agricultores percebem essa tecnologia, quais os benefícios alcançados e quais os benefícios esperados. Alguns consideram que hoje, devido à utilização do Bioágua, não tem água suja ao redor da casa, e com isso não fica mau cheiro, evidenciando, portanto, um uso racional dos resíduos, conforme Sfredo (2011).

O que esperam é uma melhor colheita, pois contam com o reúso da água para a melhoria na produção, o que proporcionaria frutas e legumes de boa qualidade para a segurança alimentar das famílias.

A proposta do Bioágua Familiar mostra-se como uma oportunidade ímpar para o alcance da sustentabilidade local. Embora seja possível inferir que há muitos aspectos a serem superados com o intuito de viabilizar essa tecnologia. Poderá contribuir para a segurança alimentar e nutricional na medida em que se torne capaz de aumentar a diversidade na produção de alimentos, por meio do reúso da água domiciliar.

\section{O BIOÁGUA E A SUSTENTABILIDADE: VIÉS ECONÔMICO, AMBIENTAL, SOCIAL E DA SEGURANÇA ALIMENTAR}

A discussão que predomina sobre sustentabilidade se faz mediante a perspectiva da multiplicidade das suas dimensões. A partir da década de 1980, o seu conceito passou a ser empregado com maior frequência, assumindo dimensões econômicas, sociais e ambientais, buscando embasar uma nova forma de desenvolvimento (SICHE, 2007; RODRIGUÉZ, 1997). Porém, os estudos de Sachs (2009) supera essa tridimensionalidade, apontando ainda as dimensões cultural, ecológica e territorial. Refere-se, ainda, à sustentabilidade política tanto no âmbito nacional como internacional. Entretanto, as dimensões envolvidas na análise da sustentabilidade não devem ser vistas de modo isolado, mas na completude das suas inter-relações. Nesse contexto, ao se analisar a segurança alimentar e nutricional de um local, critérios econômico e social, bem como as suas condições ambientais, deverão ser evidenciados.

Dessa maneira, procurou-se identificar de que maneira a tecnologia Bioágua tem resultado, ou não, em melhores condições de viabilidade da produção familiar e, consequentemente, na segurança alimentar e nutricional das famílias rurais. Para tanto, foi questionado aos agricultores quais são as culturas mais presentes no Bioágua Familiar. Os entrevistados afirmaram produzir coentro ou cheiroverde (Coriandrum sativum L.), pimentão (Capsicum annuum L.), cebolinha (Allium schoenoprasum L.), acerola (Malphigia emarginata Dc), goiaba (Psidium guajava), graviola (Annona muricata) e plantas que servem para a alimentação dos animais e para quebrar ventos, como a leucena (Leucaena spp), moringa (Moringa spp) e gliricídia (Gliricidia sepium). Antes da implantação do Bioágua, plantava-se apenas coentro e cebolinha, e em menor quantidade. Essa fragilidade na produção foi associada à ausência de assistência técnica que, antes da implantação do Bioágua, as famílias não dispunham.

Diferentes trabalhos apontam a ausência de assistência técnica como um problema que permeia a agricultura familiar. Por meio do estudo de Santos (2013), ficou evidenciado que existem diferentes entidades de assistência técnica para a agricultura familiar no município de Janduís/RN. No entanto, esse tipo de apoio não tem atendido às reais necessidades dos agricultores familiares. Também, Rozendo (2015, p. 98-99), revela haver "uma situação de muito alheamento em relação ao tema e 
fragilidade estrutural para lidar com as questões mais simples do cotidiano da assistência técnica". Essa questão acaba refletindo na falta de conhecimento das políticas de convivência com o semiárido.

Para Santos (2002, p. 25), é preciso reconhecer a viabilidade e o potencial emancipatório das diversas alternativas que "têm sido formuladas e praticadas um pouco por todo o mundo e que representam formas de organização econômica baseadas na igualdade, na solidariedade e na proteção do meio ambiente".

De acordo com a Entrevistada 4, após a implantação do Bioágua Familiar em sua unidade de produção houve um novo aprendizado sobre o manejo do solo e a importância de não fazer queimadas. Assim, afirmou: "Muita coisa a gente aprendeu. Não sabia que da maneira que a gente fazia era errado. 0 composto que eu fiz, aprendi na formação. Não sabia fazer". Convém refletir, nesse sentido, sobre a possibilidade de produção agrícola familiar e sustentabilidade, pautada nos conhecimentos novos que são apresentados, assim como a construção de novos saberes que se faz junto a esses agricultores (ALTIERRi, 2000).

Os agricultores reconhecem que o Bioágua tem colaborado para a preservação do meio ambiente, pois além de reaproveitarem a água do uso doméstico, não causam poluição, conservando o solo. Entre as práticas e cuidados para manter e melhorar a qualidade do solo citam o trabalho com compostagem, que até então não realizavam. Sobre o aspecto considerado pelos participantes da pesquisa como de maior relevância para adesão ao Bioágua Familiar consiste na alimentação de boa qualidade produzida por eles mesmos.

A seleção das famílias a serem beneficiadas com o Bioágua Familiar ocorreu quando a proposta foi apresentada na reunião da Associação Comunitária de Arrimo. Esse momento foi de sensibilizar a comunidade quanto à importância e benefícios do Bioágua. Porém, foram poucas as famílias que se mostraram estimuladas a desenvolver essa tecnologia social. Essa questão pode estar atrelada à própria dinâmica do trabalho com o Bioágua, que implica no conhecimento de uma nova tecnologia, e de tempo necessário despendido para trabalhar.

Um dos desafios para promover a perspectiva da Convivência no Semiárido consiste em sensibilizar os atores sociais locais para que compreendam que fazem parte da tessitura do novo cenário. Desse modo, as tecnologias propostas e implementadas lograrão maior êxito nessa região, a partir de novas posturas repensadas e concretizadas, conforme Campello, Carvalho e Paupitz (2015).

Referente à autonomia dos agricultores e agricultoras para definição das culturas que deverão ser produzidas, afirmam que algumas sementes são fornecidas pela Assistência Técnica, e outras a família incorpora a seu critério.

A questão principal que se coloca para a convivência com o semiárido está na adaptação inteligente aos aspectos do local, aproveitando-se as potencialidades desse ambiente sem desrespeitar o seu ecossistema. Malvezzi (2010) revela que para conviver no semiárido é preciso aproveitar as condições hídricas da região, como também a sabedoria do seu povo, de modo a tornar viável a vida nessa região.

Assim, pode-se observar que o interesse do agricultor é cultivar, também, produtos que estão de acordo com os hábitos alimentares das famílias, desde que estes sejam adaptados à região. Dentre outros, foram citados o tomate (Lycopersicon esculentum Mill), coentro (Coriandrum sativum L.), cebolinha (Allium schoenoprasum L.), alface (Lactuca sativa L.) e a cenoura (Daucus carota L.).

A construção de um modelo de desenvolvimento sustentável no semiárido perpassa a viabilização do acesso à água e ao manejo apropriado, estimulando-se, sobretudo, a produção com base sustentável e agroecológica. Baptista e Campos (2014, p. 27) consideram que:

\footnotetext{
Um princípio-chave da convivência e do desenvolvimento sustentável do semiárido é que suas populações não sejam simplesmente receptoras de conhecimentos e pacotes tecnológicos. Ao contrário, elas produzem e são capazes de gerar conhecimentos necessários ao seu desenvolvimento, sem negar a necessária interrelação com outras populações, conhecimentos e tecnologias de um modo sistêmico.
} 
A convivência com o semiárido é permeada de princípios que permitem à população ultrapassar a situação de beneficiária das políticas públicas, apresentando-se, ainda, como coautora destas. Entre outros princípios elencados, destaca-se:

[...] a valorização do patrimônio cultural, étnico, material e simbólico do semiárido; o reconhecimento da agricultura familiar como categoria sociopolítica e estratégica do desenvolvimento e o reconhecimento do meio rural como espaço de produção e reprodução da vida; a valorização das tradições e conhecimentos das comunidades; e o reconhecimento da diversidade étnica e cultural como seu patrimônio [...] (BAPTISTA; SANTOS, 2014, p. 27).

No semiárido têm sido evidenciadas práticas de famílias agricultoras que demonstram sua capacidade e potencial em desenvolver estratégias que conotam configuração de vida no campo com manejo sustentável da água e solo, e assim com a produção da alimentação para a soberania e segurança alimentar da família. Com isso, percebe-se que a convivência com o semiárido tem se constituído como um cenário que precisa ser percebido para além das dificuldades e da construção histórica dessa região.

\section{CONSIDERAÇÕES FINAIS}

Na região do semiárido potiguar têm emergido políticas públicas baseadas em tecnologias de convivência com as especificidades locais, como o Bioágua Familiar, por exemplo. Nesse sentido, identificou-se os fatores que limitam ou impulsionam a inserção das tecnologias de reúso da água no espaço rural. Percebeu-se que os fatores que dificultam consistem no convencimento das famílias em experimentar - Bioágua Familiar enquanto unidade de produção agrícola que contribui para a segurança alimentar, na limitada quantidade de água cinza utilizada pelas famílias e na pouca disponibilidade de assistência técnica para um acompanhamento mais regular e sistemático nessas unidades de produção.

Os agricultores que se apropriam dessa tecnologia social, fazem-na devido ao anseio de obter uma maior produção, que pode ser mais diversificada e sadia, considerando as condições de plantio. Também, por ser uma proposta que visa à sustentabilidade nos seus diferentes aspectos: social, na medida em que envolve a participação da família, a valorização dos recursos e da cultura local; ambiental, por meio da conservação do solo e do reúso da água cinza; e econômico, contribuindo significativamente para a segurança alimentar da família, diminuindo a necessidade de aquisição dos alimentos nos mercados locais.

É fato que a tecnologia Bioágua Familiar é importante, pois aumenta o acesso a um recurso escasso permitindo, assim, manter uma produção constante de frutas e hortaliças para o consumo alimentar das famílias. Entretanto, a pesquisa revelou as limitações dessa tecnologia, pois a água cinza gerada é insuficiente para manter o sistema sendo, frequentemente, completado com outras águas. Desse modo, a difusão dessa tecnologia depende fundamentalmente de um conjunto de estratégias de convivência com o semiárido, como as diversas tecnologias sociais que se têm desenvolvido no âmbito das políticas de captação da água de chuva (Programa Um Milhão de Cisternas e Programa Uma Terra e Duas águas). Apreende-se, então, que o Bioágua raramente poderá, sozinho, se constituir como alternativa para a produção de alimentos, se o grande gargalo ainda está no uso da água, sendo o reúso uma estratégia complementar.

Contudo, como o estudo envolve um pequeno número de amostras, vê-se a necessidade de expandi-lo para outras famílias que vivenciam essa experiência do Bioágua.

\section{NOTAS}

\footnotetext{
${ }^{1} \mathrm{~A}$ execução do Projeto ocorre no âmbito de uma estratégia integrada de desenvolvimento rural sustentável, com o patrocínio do Programa Petrobras Socioambiental; a Assessoria, Consultoria e Capacitação Técnica Orientada Sustentável (Atos) como entidade proponente e executora do projeto; com o Projeto Dom Helder Câmara (PDHC/MDA) e entidades parceiras.
}

${ }^{2} \mathrm{O}$ Projeto Dom Helder Câmara considera água cinza aquela proveniente do chuveiro, lavatório, pia de cozinha, tanque ou máquina de lavar. 


\section{REFERÊNCIAS}

ALTIERI, M.; NICHOLLS, C. I. Agroecología: teoria y práctica para una agricultura sustentable. México: Programa de las Naciones Unidas para el Medio Ambiente, 2000. (Serie Textos Básicos para la Formación Ambiental). Disponível em: <www.agro.unc.edu.ar/ biblio/AGROECOLOGIA2\%5B1\%5D.pdf>. Acesso em: 25 jan. 2013.

AZEVEDO, E. de. et al. Promoção da Saúde, Sustentabilidade e Agroecologia: uma discussão intersetorial. Saúde e Sociedade, v. 20, n. 3, p. 715-729, 2011.

BAPTISTA, N.; CAMPOS, C. H. Por um modelo de desenvolvimento sustentável no Semiárido. In: CONTI, L.; SCHROEDER, E.; MEDAGLIA, V. R. (Org.). Construindo saberes, cisternas e cidadania: formação para convivência com o semiárido brasileiro. IABS. Brasília, 2014.

BUAINAIN, A. M.; SILVEIRA, J. M. da. Jornal da UNICAMP. Universidade Estadual de Campinas. 23 a 29 de junho de 2003. Agricultura Familiar e Tecnologia no Brasil. Disponível em: <http://www.unicamp.br/unicamp/unicamp_ hoje/ju/junho2003/ju217pg02.ht>. Acesso em: 18 ago. 2011.

CAMPELLO, F. C. B.; CARVALHO, P. P. de; PAUPITZ, J. As Tecnologias são apenas mediadoras do processo de transformação social e econômica no Semiárido. Rev. Sustentabilidade em Debate. v. 6, n. 3, Brasília. p. 144-160. set/dez. 2015.

CANUTO, J. C. Agricultura ecológica en Brasil: perspectivas socioecológicas (Tese de Doutorado). Cordoba: Programa Agroecología, Campesinado e Historia. ISEC - Instituto de Sociología y Estudios Campesinos e ETSIAM - Escuela Superior de Ingenieros Agrónomos y Montes. Universidad de Córdoba. España, 1998.

CONTI, I. L. Segurança alimentar e nutricional. In: CONTI, L.; SCHROEDER, E.; MEDAGLIA, V. R. (Org.). Construindo saberes, cisternas e cidadania: formação para convivência com o semiárido brasileiro. IABS. Brasília, 2014.

DE SOUZA PICCOLI, A. et al. A Educação Ambiental como estratégia de mobilização social para o enfrentamento da escassez de água. Revista Ciência \& Saúde Coletiva, v. 21, n. 3, 2016.

DUQUE, G. "Conviver com a seca": contribuição da Articulação do Semiárido/ASA para o desenvolvimento sustentável. Desenvolvimento e Meio Ambiente, n. 17, p. 133-140, jan./jun. 2008. Editora UFPR. Disponível em: <ojs.c3sl.ufpr.br/ojs/index.php/made/article/download/13417/9043>. Acesso em: 10 mai. 2015.

FLORES, M. Agricultura familiar: desafios e perspectivas. In: Agricultura familiar e o desafio da sustentabilidade. Rio de Janeiro: Oficina Social, Centro de Tecnologia, Trabalho e Cidadania, 2001.

GRAZIANO NETO, F. Questão Agrária e Ecologia. Crítica da moderna agricultura. 2. ed. Brasiliense, São Paulo, 1985.

HESPANHOL, I. et al. Potencial de reúso de água no Brasil: agricultura, indústria, municípios, recarga de aquíferos. Revista Brasileira de Recursos Hídricos, v. 7, n. 4, p. 75-95, 2002.

LAMARCHE, H. A agricultura familiar: comparação internacional. São Paulo: Editora da Unicamp, 1993.

MALVEZZI, R. Personagens das águas. Agriculturas: experiência em agroecologia, Rio de Janeiro, v. 7, n. 3, p. 4-6, out. 2010.

OLIVEIRA, K. de S. C. Segurança alimentar e nutricional dos agricultores familiares da associação dos produtores e produtoras orgânicas de Ceará Mirim/RN. Dissertação (Mestrado) - Universidade Federal do Rio Grande do Norte. Centro de Biociências. Programa Regional de Pós-Graduação em Desenvolvimento e Meio Ambiente/ Prodema - Natal, 2015.

PLOEG, J. D. van der. Sete teses sobre a agricultura camponesa. In: PETERSEN, P. (Org). Agricultura familiar camponesa na construção do futuro. Rio de Janeiro: AS-APTA, 2009. p. 17-31

REBOUÇAS, A. da C. Água na região Nordeste: desperdício e escassez. Estudos Avançados, vol. 11, n. 29. 
RIFKIN, J. O fim dos empregos: o declínio inevitável dos níveis dos empregos e a redução da força global de trabalho. São Paulo: Makron Books, 1995.

ROCHA, J. C. da. Soberania e segurança alimentar e nutricional no Semiárido. In: CONTI, L.; SCHROEDER, E.; MEDAGLIA, V. R. (Org.). Construindo saberes, cisternas e cidadania: formação para convivência com o semiárido brasileiro. Brasília: IABS, 2014.

RODRIGUÉZ, J. M. M. Desenvolvimento sustentável: níveis conceituais e modelos. In: CAVALCANTI, A. P. B. (Org.). Desenvolvimento sustentável e planejamento: bases teóricas e conceituais. Fortaleza: UFC - Imprensa Universitária, 1997.

ROZENDO, C. Mudanças climáticas e convivência com o semiárido na agenda pública do Seridó Potiguar. Guaju, Matinhos, v. 1, n. 1, p. 90-105, jan./jun. 2015. Disponível em: <revistas.ufpr.br/guaju/article/ download/43432/26391>. Acesso em: 18 set. 2016.

SACHS, I. Caminhos para o desenvolvimento sustentável. Rio de Janeiro: Garamond, 2009, 96p.

SANTIAGO, F. dos S. [et al.]. Bioágua Familiar: reúso de água cinza para produção de alimentos no semiárido. Recife: Projeto Dom Helder Câmara, 2012.

SANTOS, B. de S. Produzir para viver: os caminhos da produção não capitalista. Rio de Janeiro: Civilização Brasileira, 2002.

SANTOS, Christiane Fernandes dos. Diagnóstico da agricultura familiar no Município de Janduís/RN: perspectiva social, econômica e ambiental. Dissertação (Pós-Graduação em Ambiente, Tecnologia e Sociedade) - Universidade Federal Rural do Semiárido. Mossoró, 2013. 102f. il.

SANTOS, Christiane Fernandes dos; MORAES, E. R. C. A metodologia do diagnóstico participativo subsidiando a pesquisa na agricultura familiar: In: Pesquisa em perspectiva: percursos metodológicos na invenção da vida e do conhecimento. FRANCISCO, D. J.; GORCZEVSKI, D.; DEMOLY, K. R. do A. (Org.). Mossoró: EdUFERSA, 2014.

SCHOTTZ, V. Em defesa da alimentação adequada e saudável. Rev. Agriculturas: Experiências em Agroecologia. v. 11, n. 4, 2014.

SFREDO, M. David e Golias unidos pela água: tecnologias avançadas colocam Israel no centro dos interesses da China. Disponível em: <http://www2.kenes.com/watec-israel/Media/Documents/brazil_1.pdf>. Acesso em: 30 mar. 2016.

SICHE, R.; et al. Índices versus indicadores: precisões conceituais na discussão da sustentabilidade de países. In: Ambiente e Sociedade. Campinas, v. 10, n. 2, jul./dez., 2007, p.137-148. Disponível em: <www.scielo.br/pdf/ asoc/v10n2/a09v10n2.pdf>. Acesso em: 28 out. 2011.

SOARES, S. F. et al. Reúso da Água na Produção de Café Cereja Descascado. Disponível em: <http://ainfo.cnptia. embrapa.br/digital/bitstream/item/86772/1/Reuso-da-agua.pdf>. Acesso em: 30 mar. 2016.

SILVA, J. G. da. O novo rural brasileiro. Coleção Pesquisas 1. Campinas: Universidade Estadual de CampinasUnicamp. Instituto de Economia, 1999.

SILVA, R. M. A. da. Entre o combate à seca e a convivência com o Semiárido: transições paradigmáticas e sustentabilidade do desenvolvimento. Tese (Doutorado em Desenvolvimento Sustentável) - UnB, Brasília, 2006. 298p.

WANDERLEY, M. de N. B. Agricultura familiar e campesinato: rupturas e continuidade. Estudos sociedade e agricultura, v. 1, 2013. 